\title{
Body mass index and waist circumference are independent risk factors for low vital capacity among Japanese participants of a health checkup: a single-institution cross-sectional study
}

\author{
Yoko Goto • Hirohide Yokokawa • Hiroshi Fukuda • \\ Toshio Naito $\cdot$ Teruhiko Hisaoka $\cdot$ Hiroshi Isonuma
}

Received: 31 October 2014/ Accepted: 25 November 2014/Published online: 5 December 2014

(C) The Japanese Society for Hygiene 2014

\begin{abstract}
Objective This study aimed to examine the associations between obesity and percentage vital capacity (\%VC), as well as lifestyle-related disorders, among Japanese participants of a voluntary health checkup.

Methods Subjects were 7,892 individuals who participated in a medical health checkup from January to December 2007. Multivariate logistic regression analysis was performed to assess associations between low \% VC $(<80)$ and body mass index (BMI) and waist circumference (WC), as well as lifestyle-related disorders.

Results Medical histories of hypertension and dyslipidemia were more frequent in the low $\% \mathrm{VC}$ group than in the normal \%VC group in both sexes. In men, BMI was significantly associated with low \%VC $(25.0 \leq \mathrm{C} 2<27.5$, odds ratio $(\mathrm{OR})=2.10 ; 27.5 \leq \mathrm{C} 3<30.0, \mathrm{OR}=2.23$; $\mathrm{C} 4 \geq 30.0, \quad \mathrm{OR}=3.46$ ) relative to the first category $(\mathrm{C} 1<25.0)$. A significant association was also observed between $\mathrm{WC}$ and low \%VC $(85 \leq \mathrm{C} 2<90$, OR $=1.40$; $90 \leq \mathrm{C} 3<95, \mathrm{OR}=1.55 ; 95 \leq \mathrm{C} 4$, OR $=2.51$; relative to $\mathrm{C} 1<85.0 \mathrm{~cm})$. In women, $\mathrm{BMI}$ was significantly associated with low \% VC in $\mathrm{C} 3$ and $\mathrm{C} 4(\mathrm{C} 3, \mathrm{OR}=2.05$; $\mathrm{C} 4, \mathrm{OR}=2.84)$, and WC was significantly associated with low \% VC in $\mathrm{C} 4(\mathrm{C} 4, \mathrm{OR}=2.32)$.

Conclusion Our results suggest that obesity may be associated with restrictive pulmonary function and underscore the
\end{abstract}

Y. Goto, H. Yokokawa contributed equally.

Y. Goto $\cdot$ H. Yokokawa $(\bowtie) \cdot$ H. Fukuda · T. Naito ·

T. Hisaoka $\cdot$ H. Isonuma

Department of General Medicine, Juntendo University School of

Medicine, 2-1-1 Hongo, Bunkyo-ku, Tokyo 113-8421, Japan

e-mail: yokokawa@pa3.so-net.ne.jp importance of maintaining ideal body weight for the prevention of restrictive pulmonary dysfunction.

Keywords Vital capacity · Restrictive respiratory dysfunction · Obesity · Metabolic syndrome · Lifestylerelated disorder

\section{Introduction}

Overweight [body mass index (BMI) $\geq 25$ ] and obesity $(\mathrm{BMI} \geq 30)$ have become global epidemics in recent years, and are attributed to changes in living standards not only in developed countries but also in developing countries [1]. In $2008,35 \%$ of adults aged $\geq 20$ years were reported to be overweight and $11 \%$ obese; in 2012, more than 40 million children aged $\leq 5$ years were reported to be overweight or obese worldwide [1]. In Japan, the prevalence of obesity (i.e., BMI $\geq 25$ ) was $29.1 \%$ in men and $19.4 \%$ in women in 2012 [2]. Obesity is a major risk factor for non-communicable disorders as well as cardiovascular disorders, and is closely related to morbidity and mortality [3, 4]. The importance of weight control has been emphasized for the primary and secondary prevention of lifestyle-related disorders worldwide [3, 4].

The associations of obesity with reduced pulmonary function and lifestyle-related disorders have received considerable attention [5-11]. In particular, a close relationship between obesity and restrictive pulmonary dysfunction has been suggested [8-11]. Moreover, restrictive pulmonary dysfunction is reportedly associated with a higher mortality rate among the elderly [12]. However, evidence is limited with regard to whether obesity is associated with vital capacity or lifestyle-related disorders among the Japanese population. In this study, we aimed to examine 
associations between vital capacity and obesity, as well as lifestyle-related disorders among Japanese participants of a voluntary health checkup.

\section{Materials and methods}

The present cross-sectional study included 11,376 Japanese individuals who participated in a medical health checkup at Yaesu Medical Heath Checkup Center in Tokyo, Japan, from January to December 2007. Of these, 3,474 were excluded due to missing data, including body weight and waist circumference (WC) $(n=2,526)$, abnormal chest X-ray findings $(n=130)$, and past and/or present medical histories of respiratory diseases $(n=818)$. Consequently, a total of 7,892 participants were included in the study.

\section{Variables}

Height $(\mathrm{m})$ and weight $(\mathrm{kg})$ were each measured in the standing position, and BMI was calculated by dividing body weight $(\mathrm{kg})$ by height squared $\left(\mathrm{m}^{2}\right)$. WC was measured with a non-stretchable tape at the level of the umbilicus in the standing position during late expiration. Respiratory function tests were performed to measure percentage vital capacity $(\% \mathrm{VC})$ and percentage forced expiratory volume $1.0 \mathrm{~s}$ (\%FEV1.0) with an automated spirometer (Autospirometer System 7, Minato Medical Science, Osaka, Japan). Blood pressure was measured using a standard mercury sphygmomanometer from the right or left arm after the participant had rested for at least $10 \mathrm{~min}$ in the sitting position. Venous blood samples were collected following overnight fasting. Serum levels of total cholesterol (mg/dL; TC), high-density lipoprotein cholesterol (mg/dL; HDL-C), low-density lipoprotein cholesterol (mg/dL; LDL-C), and triglycerides (mg/dL; TG) were also measured. LDL-C was estimated using the Friedewald equation [(TC) - (HDL-C) - (TG/5)] [13]. Glycosylated hemoglobin A1c (HbA1c) levels were determined by high-performance liquid chromatography using an automated analyzer. HbA1c values in the Japanese Diabetes Society (JDS) \% were converted to National Glycohemoglobin Standardization Program (NGSP) equivalent values using the following formula: HbA1c (NGSP \%) = $1.02 \times \mathrm{HbA} 1 \mathrm{c}(\mathrm{JDS} \%)+0.25 \%$ [14]. Past and present medical histories and lifestyle characteristics were assessed using self-administered questionnaires.

\section{Statistical analysis}

The results are presented as mean \pm standard deviation (SD) for continuous variables or prevalence (\%) for categorical variables. A two-sided student's $t$ test for continuous variables and the Chi square test for categorical variables were used to compare two groups. The values of BMI $(\mathrm{C} 1<25.0,25.0 \leq \mathrm{C} 2<27.5,27.5 \leq \mathrm{C} 3<30.0$, $\mathrm{C} 4 \geq 30.0) \quad$ and $\quad \mathrm{WC} \quad(\mathrm{C} 1<85, \quad 85 \leq \mathrm{C} 2<90$, $90 \leq \mathrm{C} 3<95, \mathrm{C} 4 \geq 95$ ) were grouped into four categories. Low $\% \mathrm{VC}$ was defined as a $\% \mathrm{VC}$ less than $80 \%$, and low \%FEV1.0 was defined as a \%FEV1.0 less than $70 \%$ according to Japanese Respiratory Society guidelines [15].

To assess whether BMI or WC was associated with low $\% \mathrm{VC}$, logistic regression analysis was performed using univariate analysis and two multivariate models for each sex: Model 1 was adjusted for age (10-year increase), BMI, $\%$ FEV1.0 ( $<70)$, atherosclerotic complications (cardiovascular and cerebrovascular diseases), medical histories (hypertension, diabetes mellitus, dyslipidemia), and smoking behavior; Model 2 was adjusted for age (10-year increase), WC, \%FEV1.0 (<70), atherosclerotic complications (cardiovascular and cerebrovascular diseases), medical histories (hypertension, diabetes mellitus, dyslipidemia), and smoking behavior. In women, the proportion of \%FEV1.0 $(<70)$ was very low, and thus \%FEV1.0 $(<70)$ was excluded from both Models 1 and 2. Dunnett's method was used to analyze associations between \% VC levels and categories of BMI and WC. All significance tests were two sided, with $P<0.05$ considered statistically significant. All data were analyzed using SPSS version 22 (IBM SPSS Inc., Chicago, USA).

The study protocol was approved by the Human Ethics Committee of Juntendo University, and written informed consent was obtained from all participants.

\section{Results}

Sex-specific characteristics $(n=7,892)$ are shown in Table 1. The mean ages of male and female participants were 55.2 (SD, 10.2) and 53.1 (11.7) years in the low \% VC group, respectively, and 48.8 (9.7) and 47.5 (10.3) years in the normal \%VC group, respectively. BMI and WC were significantly higher in the low $\% \mathrm{VC}$ group than in the normal \%VC group for both sexes [men: BMI, 24.4 (3.4) vs. 23.5 (2.9) and WC, 87.9 (9.5) vs. $85.2(7.9) \mathrm{cm}$; women: BMI, 21.9 (3.8) vs. 21.1(3.1) and WC, 80.4 (10.7) vs. $78.0(8.7) \mathrm{cm}]$. Atherosclerotic complications were more frequent in the low \% VC group than in the normal $\% \mathrm{VC}$ group for both sexes. Respiratory function tests revealed that mean $\% \mathrm{VC}$ and FEV1 were significantly lower in the low \%VC group than in the normal \%VC group for both sexes. Medical histories of hypertension and dyslipidemia were more frequent in the low $\% \mathrm{VC}$ group than in the normal \%VC group for both sexes. Medical history of diabetes mellitus was more frequent in the low $\% \mathrm{VC}$ group than in the normal \%VC group for male participants. The proportion of non-current smokers was significantly lower in the low \%VC group for men. 
Table 1 Sex-specific characteristics $(N=7,892)$

\begin{tabular}{|c|c|c|c|c|c|c|}
\hline & \multicolumn{3}{|l|}{ Men } & \multicolumn{3}{|l|}{ Women } \\
\hline & \multicolumn{3}{|c|}{ Mean $( \pm \mathrm{SD})$ or $N(\%)$} & \multicolumn{3}{|c|}{ Mean $( \pm \mathrm{SD})$ or $N(\%)$} \\
\hline & $\begin{array}{l}\text { Low \% VC }(<80) \\
(N=521)\end{array}$ & $\begin{array}{l}\text { Normal \%VC }(\geq 80) \\
(N=5006)\end{array}$ & $P$ & $\begin{array}{l}\text { Low \%VC }(<80) \\
(N=232)\end{array}$ & $\begin{array}{l}\text { Normal \%VC }(\geq 80) \\
(N=2133)\end{array}$ & $P^{\mathrm{a}}$ \\
\hline Age (years) & $55.2(10.2)$ & $48.4(9.7)$ & $* *$ & $53.1(11.7)$ & $47.5(10.3)$ & $* *$ \\
\hline \multicolumn{7}{|l|}{ Anthropometric measurements } \\
\hline Body mass index (BMI) & $24.4(3.4)$ & $23.5(2.9)$ & $* *$ & $21.9(3.8)$ & $21.1(3.1)$ & $* *$ \\
\hline Waist circumference $(\mathrm{cm})$ & $87.9(9.5)$ & $85.2(7.9)$ & $* *$ & $80.4(10.7)$ & $78.0(8.7)$ & $* *$ \\
\hline \multicolumn{7}{|l|}{ Family history (present) } \\
\hline Cardiovascular disease & $75(14.4)$ & $601(12.0)$ & & $39(16.8)$ & $307(14.4)$ & \\
\hline Cerebrovascular disease & $90(17.3)$ & $750(15.0)$ & & $43(18.5)$ & $355(16.6)$ & \\
\hline Diabetes mellitus & $61(11.7)$ & $657(13.1)$ & & $34(14.7)$ & $321(15.0)$ & \\
\hline Hypertension & $108(20.7)$ & $1103(22.0)$ & & $75(32.3)$ & $645(30.2)$ & \\
\hline Malignant neoplasm & $193(37.0)$ & $1622(32.4)$ & * & $83(35.8)$ & $744(34.9)$ & \\
\hline \multicolumn{7}{|l|}{ Atherosclerotic complications (present) } \\
\hline Cardiovascular disease & $17(3.3)$ & $77(1.5)$ & $* *$ & $5(2.2)$ & $5(0.2)$ & $* *$ \\
\hline Cerebrovascular disease & $10(1.9)$ & $19(0.4)$ & $* *$ & $4(1.7)$ & $2(0.1)$ & $* *$ \\
\hline$\%$ Vital capacity (\%VC) & $71.7(7.4)$ & $97.3(11.2)$ & $* *$ & $72.8(6.0)$ & $96.4(10.9)$ & $* *$ \\
\hline $\begin{array}{l}\% \text { Forced expiratory volume in } 1 \mathrm{~s} \\
(\% \text { FEV1.0) }\end{array}$ & $83.2(8.2)$ & $85.4(5.2)$ & $* *$ & $85.2(6.5)$ & $86.5(5.0)$ & $* *$ \\
\hline \multicolumn{7}{|l|}{ Hypertension-related factors } \\
\hline Systolic blood pressure $(\mathrm{mmHg})$ & $125.3(14.7)$ & $120.6(14.1)$ & $* *$ & $116.3(15.7)$ & $111.4(14.8)$ & $* *$ \\
\hline Diastolic blood pressure (mmHg) & $77.0(10.6)$ & $76.1(10.8)$ & & $71.4(10.9)$ & $68.6(10.3)$ & $* *$ \\
\hline Antihypertensive drug use (yes) & $117(22.5)$ & $514(10.3)$ & $* *$ & $28(12.1)$ & $107(5.0)$ & $* *$ \\
\hline \multicolumn{7}{|l|}{ Lipid-related items } \\
\hline Total cholesterol (mg/dL) & $212.0(33.9)$ & $209.5(33.1)$ & & $215.6(33.8)$ & $211.4(36.8)$ & \\
\hline $\begin{array}{l}\text { High-density lipoprotein cholesterol (mg/ } \\
\text { dL) }\end{array}$ & $61.0(14.7)$ & $64.3(16.0)$ & $* *$ & $77.4(17.4)$ & $80.0(17.7)$ & $*$ \\
\hline Low-density lipoprotein cholesterol (mg/dL) & $127.8(29.2)$ & $125.4(28.9)$ & & $124.5(29.6)$ & $119.1(31.9)$ & $*$ \\
\hline Triglycerides (mg/dL) & $158.7(136.3)$ & $137.4(100.1)$ & $* *$ & $92.8(46.8)$ & $84.0(52.1)$ & $*$ \\
\hline Antidyslipidemic drug use (yes) & $46(8.8)$ & $231(4.6)$ & $* *$ & $21(9.1)$ & $98(4.6)$ & $* *$ \\
\hline \multicolumn{7}{|l|}{ Diabetes-related items } \\
\hline Hemoglobin A1c (\%) & $5.4(0.8)$ & $5.1(0.6)$ & $* *$ & $5.1(0.5)$ & $5.0(0.4)$ & $* *$ \\
\hline Antidiabetic drug use (yes) & $25(4.8)$ & $124(2.5)$ & $* *$ & $3(1.3)$ & $10(0.5)$ & \\
\hline \multicolumn{7}{|l|}{ Healthy lifestyle characteristics } \\
\hline $\begin{array}{l}\text { Alcohol consumption (non-everyday } \\
\text { drinker) }\end{array}$ & $358(68.7)$ & $3438(68.7)$ & & $216(93.1)$ & $1930(90.5)$ & \\
\hline Smoking behavior (non-current smoker) & $294(57.1)$ & $3211(65.9)$ & $* *$ & $210(92.5)$ & $1890(91.0)$ & \\
\hline $\begin{array}{l}\text { Exercise frequency (two times or more per } \\
\text { week) }\end{array}$ & $452(86.8)$ & $4323(86.4)$ & & $189(81.5)$ & $1836(86.1)$ & \\
\hline Sleep hours (7-9) & 169 (32.9) & $1107(22.8)$ & $* *$ & $48(21.1)$ & $552(26.6)$ & \\
\hline Breakfast (every morning) & $441(84.6)$ & $4048(80.9)$ & $*$ & $212(91.4)$ & $1885(88.4)$ & \\
\hline Snack between meals (no) & $404(77.5)$ & $3954(79.0)$ & & $144(62.1)$ & $1320(61.9)$ & \\
\hline $\begin{array}{l}\text { Proportion of participants with } 5 \text { or } 6 \\
\text { number of healthy lifestyle items }\end{array}$ & $194(37.9)$ & $1790(37.0)$ & & $109(48.7)$ & $1037(50.3)$ & \\
\hline
\end{tabular}

Figures 1, 2, 3 and 4 show associations between BMI/ $\mathrm{WC}$ and \%VC. In men, \%VC was significantly lower in those with $\mathrm{BMI} \geq 25.0$ or $\mathrm{WC} \geq 85 \mathrm{~cm}$ compared to those with $\mathrm{BMI}<25.0(P<0.01)$ or $\mathrm{WC}<85 \mathrm{~cm}$ $(P<0.01)$. In women, \%VC was significantly lower in those with $\mathrm{BMI} \geq 30.0$ or $\mathrm{WC} \geq 95 \mathrm{~cm}$ compared to 


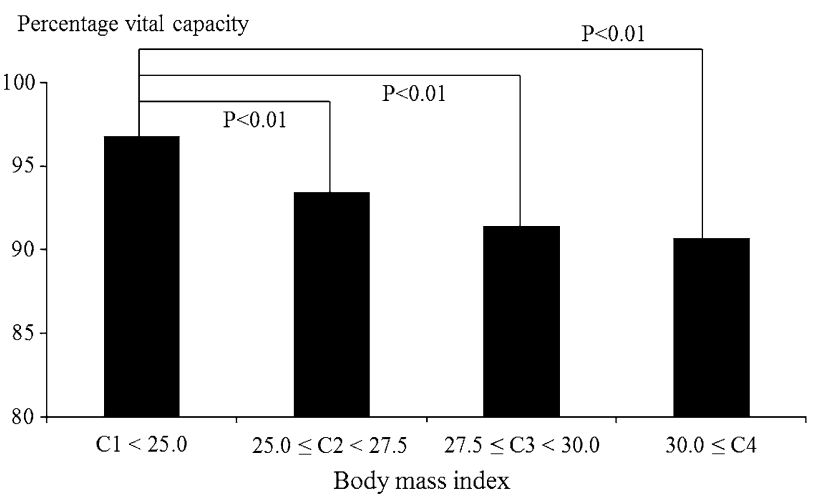

Fig. 1 Associations between body mass index and percentage vital capacity among male participants. Statistical significance was estimated by Dunnett's method

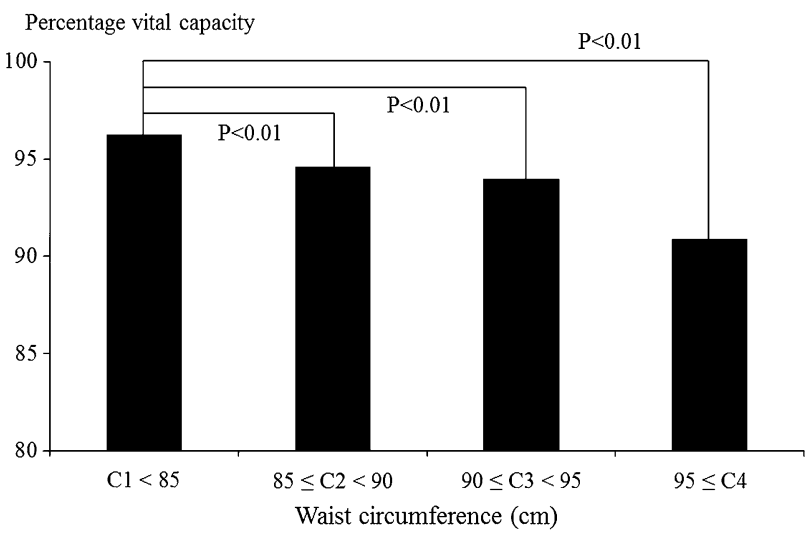

Fig. 2 Associations between waist circumference and percentage vital capacity among male participants. Statistical significance was estimated by Dunnett's method

those with $\mathrm{BMI}<25.0 \quad(P=0.02)$ or $\mathrm{WC}<85 \mathrm{~cm}$ $(P<0.01)$.

Multivariate logistic regression analysis was performed to determine factors associated with low \% VC (Tables 2, $3)$. In men $(n=5527)$, Model 1 showed that the second, third, and fourth categories of BMI were significantly associated with low \% VC relative to the first category. WC was also significantly associated with low \%VC. In women $(n=2365), \mathrm{C} 3$ and $\mathrm{C} 4$ of BMI were significantly associated with low $\% \mathrm{VC}$ relative to $\mathrm{C} 1$, and $\mathrm{C} 4$ of $\mathrm{WC}$ was significantly associated with low $\% \mathrm{VC}$ relative to $\mathrm{C} 1$.

\section{Discussion}

In this single-institution study, BMI and WC, i.e., obesityrelated parameters, were significantly associated with low $\% \mathrm{VC}$ after adjusting for confounding factors in both sexes. To the best of our knowledge, only a few reports have

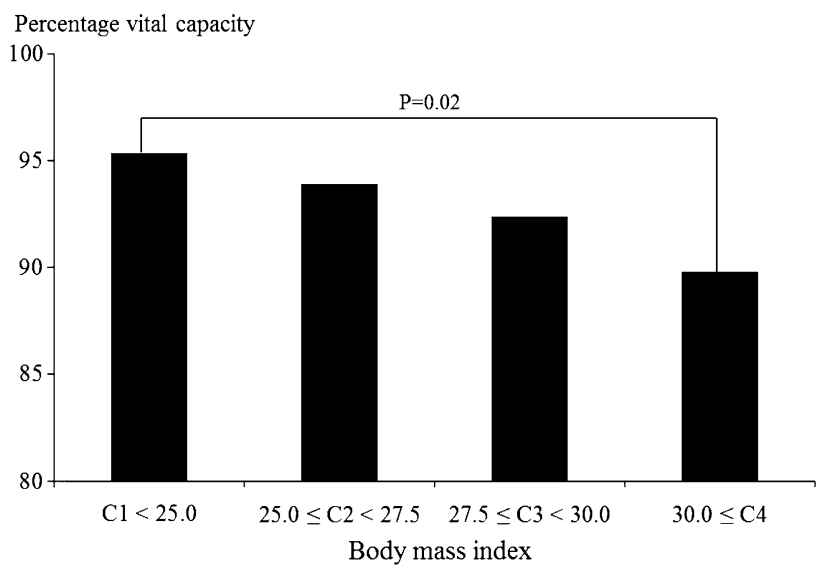

Fig. 3 Associations between body mass index and percentage vital capacity among female participants. Statistical significance was estimated by Dunnett's method

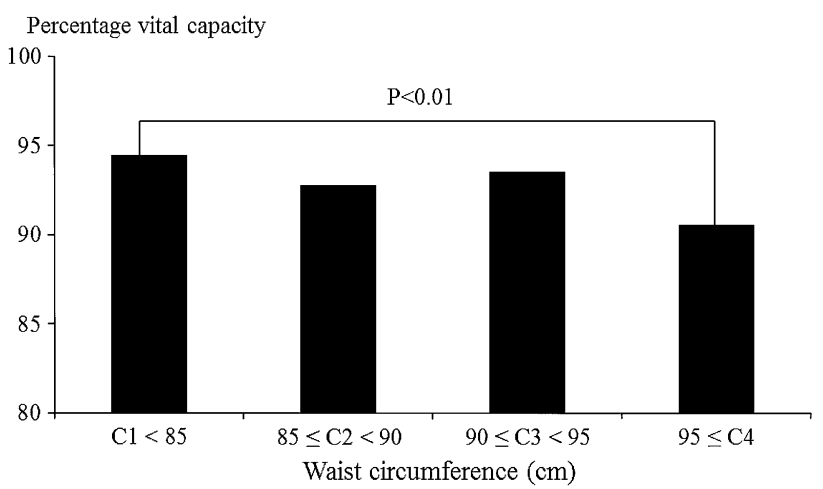

Fig. 4 Associations between waist circumference and percentage vital capacity among female participants. Statistical significance was estimated by Dunnett's method

focused on the association between obesity and restrictive ventilatory impairment as reflected by a low $\% \mathrm{VC}$ in the Japanese population and our results may be one of the important evidences to assess the association.

Several studies have examined associations between pulmonary function and obesity. A Japanese cross-sectional study reported that $\mathrm{BMI}$ and $\mathrm{WC}$ were significantly higher in Japanese men with $\% \mathrm{VC} \leq 95$ compared to those with $\% \mathrm{VC} \geq 96$ [8]. Another cross-sectional study in Italy reported that a restrictive respiratory pattern was significantly associated with visceral obesity among components of metabolic syndrome [16]. Although the mechanism underlying the association between obesity and low \% VC has not been elucidated, one possible explanation is thoracic restriction associated with obesity $[7,17]$, which is attributed to the mechanical effects of fat on the diaphragm and chest wall. The Normative Aging Study, which examined the effects of overall obesity and fat distribution on ventilatory function in 507 Australians, reported that 
BMI was positively associated with the ratio of FEV1 to FVC at all ages, and negatively with FVC between 40 and 69 years [7]. The EPIC-Norfolk study conducted in the UK reported on the association between abdominal fat deposition and impairment of respiratory function, and demonstrated that both FEV1 and FVC were linearly and inversely related across the entire range of waist to hip ratio in both men and women [17].

Another possible explanation is respiratory muscle weakness associated with obesity, which is attributed to muscle inefficiency due to reduced chest wall compliance and/or lower operating lung volumes $[18,19]$. A previous study reported a significantly higher noninvasive tension time index of inspiratory muscle (TTmus) in obese subjects $(\mathrm{BMI}>30)$ compared to controls, and a significant positive correlation between TTmus and BMI [19]. In our study, BMI and WC were significantly associated with low \% VC, suggesting that an imbalance between thoracic restriction and respiratory muscle weakness may lead to decreased \%VC in those with obesity. Thus, our data underscores the importance of weight control in maintaining or improving respiratory condition.

In the comparison between low and normal \%VC groups, a higher prevalence of lifestyle-related disorders may be observed in the low \% VC group compared to the normal \%VC group in both sexes. To date, several studies have reported on the association between low $\mathrm{VC}$ and lifestyle-related disorders [8-11]. In the USA, a prospective cohort study of 11,479 middle-aged adults without

Table 2 Factors associated with low $\%$ vital capacity among male participants $(N=5527)$ (logistic regression analysis)

\begin{tabular}{|c|c|c|c|c|c|c|c|c|c|c|}
\hline & \multicolumn{4}{|c|}{ Univariate analysis } & \multicolumn{3}{|c|}{ Model $1^{\mathrm{c}}$} & \multicolumn{3}{|c|}{ Model $2^{\mathrm{d}}$} \\
\hline & $N(\%)$ & $\mathrm{OR}^{\mathrm{a}}$ & $95 \% \mathrm{CI}^{\mathrm{b}}$ & $P$ & $\mathrm{OR}^{\mathrm{a}}$ & $95 \% \mathrm{CI}^{\mathrm{b}}$ & $P$ & $\mathrm{OR}^{\mathrm{a}}$ & $95 \% \mathrm{CI}^{\mathrm{b}}$ & $P$ \\
\hline Age (years) ${ }^{\mathrm{e}}$ & & 1.87 & $1.71-2.04$ & $* *$ & 1.98 & $1.81-2.17$ & $* *$ & 1.85 & $1.68-2.04$ & $* *$ \\
\hline \multicolumn{11}{|l|}{ Anthropometric measurements } \\
\hline \multicolumn{11}{|l|}{ Body mass index (BMI) } \\
\hline $\mathrm{C} 1<25.0$ & $3990(72.2)$ & \multicolumn{3}{|c|}{ Reference } & \multicolumn{3}{|c|}{ Reference } & & & \\
\hline $25.0 \leq \mathrm{C} 2<27.5$ & $1040(18.8)$ & 2.11 & $1.71-2.60$ & $* *$ & 2.10 & $1.72-2.56$ & $* *$ & & & \\
\hline $27.5 \leq \mathrm{C} 3<30.0$ & $331(6.0)$ & 2.25 & $1.63-3.10$ & $* *$ & 2.37 & $1.75-3.23$ & $* *$ & & & \\
\hline $30.0 \leq \mathrm{C} 4$ & $166(3.0)$ & 2.67 & $1.76-4.06$ & $* *$ & 3.46 & $2.34-5.12$ & $* *$ & & & \\
\hline \multicolumn{11}{|l|}{ Waist circumference $(\mathrm{cm})$} \\
\hline $\mathrm{C} 1<85$ & $2614(47.3)$ & \multicolumn{3}{|c|}{ Reference } & & & & \multicolumn{3}{|c|}{ Reference } \\
\hline $85 \leq \mathrm{C} 2<90$ & $1419(25.7)$ & 1.51 & $1.20-1.90$ & $* *$ & & & & 1.40 & $1.10-1.78$ & $* *$ \\
\hline $90 \leq \mathrm{C} 3<95$ & $833(15.1)$ & 1.73 & $1.14-2.25$ & $* *$ & & & & 1.55 & $1.17-2.03$ & $* *$ \\
\hline $95 \leq \mathrm{C} 4$ & $661(12.0)$ & 2.65 & $2.06-3.41$ & $* *$ & & & & 2.51 & $1.92-3.30$ & $* *$ \\
\hline$\%$ Forced expiratory volume in $1 \mathrm{~s}(\% \mathrm{FEV} 1.0<70)$ & $59(1.1)$ & 8.50 & $5.05-14.30$ & $* *$ & 5.74 & $3.65-9.01$ & $* *$ & 6.96 & $3.97-12.21$ & $* *$ \\
\hline \multicolumn{11}{|l|}{ Atherosclerotic complications } \\
\hline Cardiovascular disease (present) & $94(1.7)$ & 2.16 & $1.27-3.68$ & $* *$ & 1.18 & $0.70-1.98$ & & 1.11 & $0.62-1.97$ & \\
\hline Cerebrovascular disease (present) & $29(0.5)$ & 5.14 & $2.38-11.11$ & $* *$ & 2.08 & $0.93-4.65$ & & 2.11 & $0.89-5.00$ & \\
\hline \multicolumn{11}{|l|}{ Medical histories } \\
\hline Antihypertensive drug use (yes) & $631(11.4)$ & 2.53 & $2.02-3.17$ & $* *$ & 1.21 & $0.96-1.53$ & & 1.36 & $1.05-1.75$ & $*$ \\
\hline Antidiabetic drug use (yes) & $149(2.7)$ & 1.98 & $1.28-3.08$ & $* *$ & 1.16 & $0.76-1.77$ & & 1.16 & $0.72-1.85$ & \\
\hline Antidyslipidemic drug use (yes) & $277(5.0)$ & 2.00 & $1.44-2.79$ & $* *$ & 1.31 & $0.95-1.81$ & & 1.24 & $0.87-1.77$ & \\
\hline \multicolumn{11}{|l|}{ Healthy lifestyle characteristics } \\
\hline Smoking behavior (non-current smoker) & $3505(63.4)$ & 0.69 & $0.57-0.83$ & $* *$ & 0.58 & $0.48-0.69$ & $* *$ & 0.55 & $0.46-0.67$ & $* *$ \\
\hline
\end{tabular}

$* P<0.05$

$* * P<0.01$

a Odds ratio

b $95 \%$ confidence interval

c Model 1 was adjusted for age (10-year increase), body mass index, percentage forced expiratory volume in $1 \mathrm{~s}(<70)$, atherosclerotic complications (cardiovascular and cerebrovascular diseases), medical history (hypertension, diabetes mellitus, dyslipidemia), and smoking behavior

${ }^{\mathrm{d}}$ Model 2 was adjusted for age (10-year increase), waist circumference, percentage forced expiratory volume in $1 \mathrm{~s}(<70)$, atherosclerotic complications (cardiovascular and cerebrovascular diseases), medical history (hypertension, diabetes mellitus, dyslipidemia), and smoking behavior

e 10-year increase 
Table 3 Factors associated with low \% vital capacity among female participants $(N=2365)$ (logistic regression analysis)

\begin{tabular}{|c|c|c|c|c|c|c|c|c|c|c|}
\hline & \multicolumn{4}{|c|}{ Univariate analysis } & \multicolumn{3}{|c|}{ Model $1^{\mathrm{c}}$} & \multicolumn{3}{|c|}{ Model $2^{\mathrm{d}}$} \\
\hline & $N(\%)$ & $\mathrm{OR}^{\mathrm{a}}$ & $95 \% \mathrm{CI}^{\mathrm{b}}$ & $P$ & $\mathrm{OR}^{\mathrm{a}}$ & $95 \% \mathrm{CI}^{\mathrm{b}}$ & $P$ & $\mathrm{OR}^{\mathrm{a}}$ & $95 \% \mathrm{CI}^{\mathrm{b}}$ & $P$ \\
\hline Age (years) & & 1.58 & $1.39-1.79$ & $* *$ & 1.53 & $1.35-1.73$ & $* *$ & 1.46 & $1.28-1.68$ & $* *$ \\
\hline \multicolumn{11}{|l|}{ Anthropometric measurements } \\
\hline \multicolumn{11}{|l|}{ Body mass index (BMI) } \\
\hline $\mathrm{C} 1<25.0$ & $2107(89.1)$ & & & & & & & & & \\
\hline $25.0 \leq \mathrm{C} 2<27.5$ & $150(6.3)$ & 1.27 & $0.75-2.15$ & & 1.23 & $0.77-1.96$ & & & & \\
\hline $27.5 \leq \mathrm{C} 3<30.0$ & $58(2.5)$ & 2.32 & $1.18-4.55$ & $*$ & 2.05 & $1.07-3.92$ & $*$ & & & \\
\hline $30.0 \leq \mathrm{C} 4$ & $50(2.1)$ & 2.80 & $1.41-5.55$ & $* *$ & 2.84 & $1.50-5.40$ & $* *$ & & & \\
\hline \multicolumn{11}{|l|}{ Waist circumference $(\mathrm{cm})$} \\
\hline $\mathrm{C} 1<85$ & $1864(78.8)$ & & & & & & & & & \\
\hline $85 \leq \mathrm{C} 2<90$ & $253(10.7)$ & 1.45 & $1.19-1.75$ & $* *$ & & & & 1.28 & $0.85-1.95$ & \\
\hline $90 \leq \mathrm{C} 3<95$ & $149(6.3)$ & 1.71 & $1.37-2.104$ & $* *$ & & & & 1.44 & $0.87-2.39$ & \\
\hline $95 \leq \mathrm{C} 4$ & $99(4.2)$ & 2.61 & $2.10-3.25$ & $* *$ & & & & 2.32 & $1.35-4.00$ & $* *$ \\
\hline \multicolumn{11}{|l|}{ Atherosclerotic complications } \\
\hline Cardiovascular disease (present) & $10(0.4)$ & 9.37 & $2.69-32.63$ & $* *$ & 2.30 & $0.78-6.77$ & & 7.02 & $1.94-25.40$ & $*$ \\
\hline Cerebrovascular disease (present) & $6(0.3)$ & 18.69 & $3.41-102.62$ & $* *$ & 9.19 & $1.52-55.62$ & $*$ & 8.11 & $1.30-50.72$ & $*$ \\
\hline \multicolumn{11}{|l|}{ Medical history } \\
\hline Antihypertensive drug use (yes) & $135(5.7)$ & 2.60 & $1.67-4.04$ & $* *$ & 1.15 & $0.71-1.85$ & & 1.32 & $0.79-2.19$ & \\
\hline Antidiabetic drug use (yes) & $13(0.5)$ & 2.78 & $0.76-10.18$ & & 0.68 & $0.15-3.21$ & & 1.17 & $0.24-5.63$ & \\
\hline Antidyslipidemic drug use (yes) & $119(5.0)$ & 2.07 & $1.26-3.38$ & $* *$ & 1.10 & $0.66-1.84$ & & 0.89 & $0.50-1.60$ & \\
\hline \multicolumn{11}{|l|}{ Healthy lifestyle characteristics } \\
\hline Smoking behavior (non-current smoker) & $2100(88.8)$ & 1.22 & $0.73-2.05$ & & 1.13 & $0.71-1.80$ & & 0.99 & $0.60-1.97$ & \\
\hline
\end{tabular}

$* P<0.05$

$* * P<0.01$

a Odds ratio

b $95 \%$ confidence interval

c Model 1 was adjusted for age (10-year increase), body mass index, atherosclerotic complications (cardiovascular and cerebrovascular diseases), medical history (hypertension, diabetes mellitus, dyslipidemia), and smoking behavior

${ }^{\mathrm{d}}$ Model 2 was adjusted for age (10-year increase), waist circumference, atherosclerotic complications (cardiovascular and cerebrovascular diseases), medical history (hypertension, diabetes mellitus, dyslipidemia), and smoking behavior

e 10 -year increase

diabetes at baseline reported that the fully adjusted hazard ratio $(95 \% \mathrm{CI})$ of diabetes in individuals in the lowest quartile was $1.6(1.3-2.0)$ in men and $1.7(1.3-2.1)$ in women, demonstrating that lower VC was an independent predictor of incident type 2 diabetes [10]. In Japan, a crosssectional study reported that lower VC was significantly associated with diabetes and metabolic syndrome in men, although the relationship was not conclusive in women [9]. Another cross-sectional study reported that a decreased $\%$ VC was associated with diabetes, hypertension, hypertriglyceridemia, and cardiovascular disorders among 954 Japanese men [11]. Interestingly, the National Health and Nutrition Examination Survey Epidemiologic Follow-Up Study reported that obstructive lung disease (defined by the Global Initiative for Chronic Obstructive Lung Disease classification) was not significantly associated with the incidence of diabetes, while restrictive lung disease was (hazard ratio $=1.45,95 \%$ CI 1.04-2.03) [20]. Several possible explanations have been proposed, including insulin resistance [21] and chronic inflammation [22, 23]. A Swedish population-based cohort study reported that subjects with a moderately reduced FVC have an increased risk of developing insulin resistance and diabetes [21]. Moreover, a cross-sectional study that examined associations between pulmonary function, metabolic abnormality, and metabolic syndrome among 2,396 healthy Japanese adults reported that hs-CRP and impaired restrictive pulmonary function, but not obstructive pulmonary function, were significantly associated with metabolic syndrome [22]. These studies may suggest the need to examine lung function in those with obesity during a health checkup. $\mathrm{BMI}$ and WC were significantly associated with low \% VC, but not with lifestyle-related disorders in multivariate regression analysis. The results may suggest that obesity 
was strongly associated with low \%VC rather than lifestyle-related disorders. Thus, we should pay more attention to obesity in considering lung function.

This study has several limitations. First, a possible selection bias cannot be denied, given that the study was conducted in a single health checkup institution in Tokyo, Japan, and that participants were limited to those who voluntarily underwent a medical checkup, i.e., participants may have had increased awareness of health conditions and healthy lifestyle practices. Moreover, the present study did not collect important variables, such as hs-CRP, immunereactive insulin, and adiponectin, and thus could not evaluate patients in terms of insulin resistance and chronic inflammatory status. Future studies should include these variables. Finally, the present study used a cross-sectional analysis, and causal relationships between obesity and $\% \mathrm{VC}$ could not be fully elucidated. Further analyses of follow-up survey data are needed.

In conclusion, this cross-sectional study revealed that $\mathrm{BMI} \geq 25$ and $\mathrm{WC} \geq 85 \mathrm{~cm}$ for men, and $\mathrm{BMI} \geq 27.5$ and $\mathrm{WC} \geq 95 \mathrm{~cm}$ for women were significantly associated with low \%VC $(<80)$ among Japanese participants. Our findings suggest a possible association between obesity and restrictive pulmonary function and underscore the importance of maintaining ideal body weight to prevent restrictive pulmonary dysfunctions.

Acknowledgments The authors thank the participants who underwent the voluntary medical checkup and the data collection staff at Yaesu Medical Heath Checkup Center. This study was funded by a 2012 Grant-in-Aid for Scientific Research (C) (No. 24590816).

Conflict of interest The authors have no conflicts of interest to declare.

\section{References}

1. WHO. Obesity and overweight. Fact sheet No. 311. Geneva, Switzerland. 2013. http://www.who.int/mediacentre/factsheets/ fs311/en/. Accessed 15 Oct 2014.

2. Ministry of Health, Labour and Welfare, Report on health and nutrition survey 2012. 2013. http://www.mhlw.go.jp/file/04-Hou douhappyou-10904750-Kenkoukyoku-Gantaisakukenkouzoush inka/0000032813.pdf. Accessed 15 Oct 2014.

3. Kontis V, Mathers CD, Rehm J, Stevens GA, Shield KD, Bonita $\mathrm{R}$, et al. Contribution of six risk factors to achieving the $25 \times 25$ non-communicable disease mortality reduction target: a modelling study. Lancet. 2014;384:427-37.

4. Lu Y, Hajifathalian K, Ezzati M, Woodward M, Rimm EB, Danaei G, et al. Global Burden Of Metabolic Risk Factors For Chronic Diseases Collaboration (BMI Mediated Effects), metabolic mediators of the effects of body-mass index, overweight, and obesity on coronary heart disease and stroke: a pooled analysis of 97 prospective cohorts with 1.8 million participants? Lancet. 2014;383:970-83.

5. Poulain M, Doucet M, Major GC, Drapeau V, Sériès F, Boulet LP, et al. The effect of obesity on chronic respiratory diseases: pathophysiology and therapeutic strategies. CMAJ. 2006;174: 1293-9.

6. Mannino DM, Ford ES, Redd SC. Obstructive and restrictive lung disease and markers of inflammation: data from the Third National Health and Nutrition Examination. Am J Med. 2003;114:758-62.

7. Lazarus R, Sparrow D, Weiss ST. Effects of obesity and fat distribution on ventilatory function: the normative aging study. Chest. 1997;111:891-8.

8. Oda E, Kawai R. Low vital capacity is associated with diabetes despite inverse relationships with metabolic risk factors in lean Japanese men. Intern Med. 2009;48:1201-7 Epub 2009 Jul 15.

9. Oda E, Kawai R. A cross-sectional relationship between vital capacity and metabolic syndrome and between vital capacity and diabetes in a sample Japanese population. Environ Health Prev Med. 2009;14:284-91.

10. Yeh HC, Punjabi NM, Wang NY, Pankow JS, Duncan BB, Brancati FL, et al. Vital capacity as a predictor of incident type 2 diabetes: the Atherosclerosis Risk in Communities study. Diabetes Care. 2005;28:1472-9.

11. Sakuta H, Suzuki T, Yyasuda H, Ito T. Vital capacity and selected metabolic diseases in middle-aged Japanese men. Can Respir J. 2006;13:79-82.

12. Scarlata S, Pedone C, Fimognari FL, Bellia V, Forastiere F, Incalzi RA, et al. Restrictive pulmonary dysfunction at spirometry and mortality in the elderly. Respir Med. 2008;102:1349-54.

13. Warnick GR, Knopp RH, Fitzpatrick V, Branson L. Estimating low-density lipoprotein cholesterol by the Friedewald equation is adequate for classifying patients on the basis of nationally recommended cut points. Clin Chem. 1990;36:15-9.

14. Kashiwagi A, Kasuga M, Araki E, Oka Y, Hanafusa T, Ito H, et al. Committee on the Standardization of Diabetes MellitusRelated Laboratory Testing of Japan Diabetes Society. International clinical harmonization of glycated hemoglobin in Japan : from Japan Diabetes Society to National Glycohemoglobin Standardization Program values. J Diabetes Investig. 2012;3: $39-40$.

15. The Specific Committee of the Japanese Respiratory Society on the lung physiology. Respiratory function test Guideline; Evaluation of Spirometry. Osaka: Medical Review Co., Ltd; 2004. p. 20-3 In Japanese.

16. Fimognari FL, Pasqualetti P, Moro L, Franco A, Piccirillo G, Pastorelli $\mathrm{R}$, et al. The association between metabolic syndrome and restrictive ventilatory dysfunction in older persons. J Gerontol A Biol Sci Med Sci. 2007;62:760-5.

17. Canoy D, Luben R, Welch A, Bingham S, Wareham N, Day N, et al. Abdominal obesity and respiratory function in men and women in the EPIC-Norfolk Study, United Kingdom. Am J Epidemiol. 2004;159:1140-9.

18. Weiner P, Waizman J, Weiner M, Rabner M, Magadle R, Zamir $\mathrm{D}$, et al. Influence of excessive weight loss after gastroplasty for morbid obesity on respiratory muscle performance. Thorax. 1998:53:39-42.

19. Chlif M, Keochkerian D, Mourlhon C, Choquet D, Ahmaidi S. Noninvasive assessment of the tension-time index of inspiratory muscles at rest in obese male subjects. Int $\mathrm{J}$ Obes (Lond). 2005;29:1478-83.

20. Ford ES, Mannino DM. Prospective association between lung function and the incidence of diabetes: findings from the National Health and Nutrition Examination Survey Epidemiologic Followup Study. Diabetes Care. 2004;27:2966-70.

21. Engström G, Hedblad B, Nilsson P, Wollmer P, Berglund G, Janzon $\mathrm{L}$, et al. Lung function, insulin resistance and incidence of cardiovascular disease: a longitudinal cohort study. J Intern Med. 2003;253:574-81. 
22. Nakajima K, Kubouchi Y, Muneyuki T, Ebata M, Eguchi S, Munakata $\mathrm{H}$, et al. A possible association between suspected restrictive pattern as assessed by ordinary pulmonary function test and the metabolic syndrome. Chest. 2008;134:712-8.
23. Oda E, Kawai R. A cross-sectional relationship between vital capacity and metabolic syndrome and between vital capacity and diabetes in a sample Japanese population. Environ Health Prev Med. 2009;14:284-91. 